\title{
An efficient parameter identification procedure for soft sensitive clays"
}

\author{
Liang YE ${ }^{\dagger 1}$, Yin-fu JIN ${ }^{\dagger 2,3}$, Shui-long SHEN ${ }^{2}$, Ping-ping SUN ${ }^{4}$, Cheng ZHOU ${ }^{5}$ \\ $\left({ }^{1}\right.$ Department of Civil Engineering, Zhejiang University of Science and Technology, Hangzhou 310012, China) \\ $\left({ }^{2}\right.$ State Key Laboratory of Ocean Engineering, School of Naval Architecture, Ocean, and Civil Engineering, \\ Shanghai Jiao Tong University, Shanghai 200240, China) \\ ( ${ }^{3}$ LUNAM University, Ecole Centrale de Nantes, GeM UMR CNRS, 6183, Nantes, France) \\ ( ${ }^{4}$ Department of Civil Engineering, Zhejiang University of Water Resources and Electric Power, Hangzhou 310018, China) \\ ( ${ }^{5}$ State Key Laboratory of Hydraulics and Mountain River Engineering, College of Water Resource \& Hydropower, \\ Sichuan University, Chengdu 610065, China) \\ †E-mail: yeliang88@126.com; yinfu.jin9019@gmail.com
}

Received Feb. 5, 2015; Revision accepted June 26, 2015; Crosschecked Dec. 11, 2015

\begin{abstract}
The creep and destructuration characteristics of soft clay are always coupled under loading, making it difficult for engineers to determine these related parameters. This paper proposes a simple and efficient optimization procedure to identify both creep and destructuration parameters based on low cost experiments. For this purpose, a simplex algorithm (SA) with random samplings is adopted in the optimization. Conventional undrained triaxial tests are performed on Wenzhou clay. The newly developed creep model accounting for the destructuration is enhanced by anisotropy of elasticity and adopted to simulate tests. The optimal parameters are validated first by experimental measurements, and then by simulating other tests on the same clay. Finally, the proposed procedure is successfully applied to soft Shanghai clay. The results demonstrate that the proposed optimization procedure is efficient and reliable in identifying creep and destructuration related parameters.
\end{abstract}

Key words: Clay, Creep, Destructuration, Optimization, Simplex, Parameter identification http://dx.doi.org/10.1631/jzus.A1500031

CLC number: TU4

\section{Introduction}

Soft clays are widely distributed in many regions, such as along rivers, lakes, and coasts, and their behavior is important to the construction of infrastructure. The initial soil structure of soft clays and their destructuring behavior, which is defined by the

\footnotetext{
${ }^{\ddagger}$ Corresponding author

* Project supported by the National Natural Science Foundation of China (No. 41372283), the European Project CREEP (No. PIAPP-GA-2011-286397), and the French Ministry of Research through ANR-RISMOGEO

(iD) ORCID: Liang YE, http://orcid.org/0000-0001-7943-1206; Yin-fu JIN, http://orcid.org/0000-0003-0522-1702

(C) Zhejiang University and Springer-Verlag Berlin Heidelberg 2016
}

bond between soil particles, are important considerations. Due to the effects of sedimentation and chemical action, the structure exists more or less in the natural clays (Leroueil and Vaughan, 1990; Yin and Hicher, 2008; Karstunen and Yin, 2010; Yin et al., 2010a; 2010b; 2010c; 2011a; 2011b; 2014; 2015a; 2015b; Yin and Karstunen, 2011; Yin and Wang, 2012; Wang and Yin, 2015). Another significant behavior of soft clay is creep. When soft sensitive clay is subjected to external loading, the degradation of the structure and creep are always coupled, which affects the engineering properties of soft clays. As a result, the parameters related to creep and structure cannot easily be measured directly from experiments. More tests are needed to obtain these parameters, 
such as those performed on both intact and remolded samples, which significantly raises the experimental cost in engineering applications. Therefore, how to identify these parameters in an efficient and economical way becomes a challenge.

Different inverse analysis techniques for identifying soil parameters have recently been successfully used in geotechnical fields. These applications involved different kinds of tests, such as laboratory tests (Calvello and Finno, 2004) and field tests (Lecampion et al., 2002; Yin and Hicher, 2008; Papon et al., 2012), which were performed on different soils. Different constitutive models, such as the Mohr-Coulomb model (Papon et al., 2012), hardening soil model (Calvello and Finno, 2004; Papon et al., 2012), and modified Cam clay model (Dano et al., 2007), have been adopted and combined with these tests in the optimization process to identify their parameters. However, no studies about the identification of parameters relating to creep combined with destructuration of structured clays using optimization techniques has been reported. Therefore, it is worth seeking an effective and reliable optimization method for identifying creep and destructuration related parameters.

In this paper, an optimization procedure using a simplex algorithm (SA) is proposed to identify the parameters relating to creep and destructuration. Undrained triaxial compression tests performed on Wenzhou marine clay were selected as the objective for the optimization. The newly developed creep model accounting for the destructuration was enhanced with anisotropy of elasticity and adopted to simulate the undrained triaxial compression tests. The procedure was validated by comparison with other experimental measurements and by simulating other tests of the same clay. Finally, the feasibility of the optimization procedure was further validated by identifying parameters of soft Shanghai clay.

\section{Procedure of parameter identification}

\subsection{Error function}

An advanced error function proposed by Levasseur et al. (2008) was adopted in this study, and is defined as the relative error between the experimental and the computed values:

$$
\operatorname{Error}(\boldsymbol{x})=\sqrt{\frac{\sum_{i=1}^{N}\left(\frac{U_{\exp }^{i}-U_{\mathrm{num}}^{i}}{U_{\exp }^{i}} \times 100\right)^{2}}{N}} \%,
$$

where $\boldsymbol{x}$ is the vector of parameters; $N$ is the number of values; $U_{\exp }^{i}$ is the value of measurement point $i$; $U_{\text {num }}^{i}$ is the value of calculation at point $i$. The effects of scale on the fitness between experimental and simulated results can be eliminated using this normalized formulation. Also, the objective error calculated by this function is a dimensionless variable, thus, differences of error can be avoided for different objectives with different variables.

\subsection{Simplex algorithm and initialization method}

The SA is a nonlinear optimization algorithm developed by Nelder and Mead (1965) for minimizing an objective function in a poly-dimensional space. The method uses the concept of a simplex, which is a polytope of $N+1$ vertices in $N$ dimensions, and finds a locally optimal solution to a problem with $N$ variables when the objective function varies smoothly.

The simplest step is to replace the worst point with a point reflected through the centroid of the remaining $N$ points. The Nelder-Mead simplex can change in five different ways during iteration (Fig. 1) in two dimensions (Lagarias et al., 1998). Except in the case of a shrink, the worst vertex of the simplex at iteration $k$ (point $p_{3}$ in Fig. 1) is replaced at iteration $k+1$ by one of the reflection, expansion, or contraction points. If this new point is not much better than the previous value, then we are stepping across a valley, so we shrink the simplex towards the best point. Based on this description, users feel that they understand what the method is doing. The simplex can lead to the best solution using a limited number of calculations. In that sense, it can be fast and efficient.

Among many parameters controlling the optimization methods, those related to the initial simples are important. The initial simplex is governed by the number of the individuals, their domain (range), and the method controlling the distribution of the individuals within their domain. In this case, an advanced random (Monte Carlo) sampling method named uniform Latin hypercube (ULH) (McKay et al., 1979) was adopted. Compared to simple random (Monte Carlo) sampling, ULH is better at mapping the 
marginal probability distributions, especially in the case of a small number of generated designs.

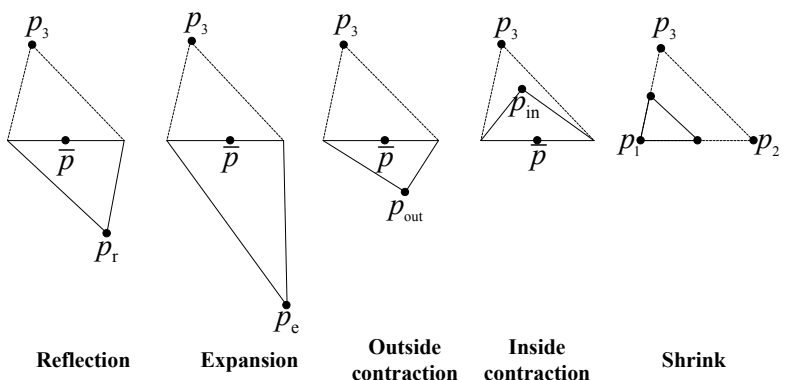

Fig. 1 Structure of Nelder-Mead simplex algorithm after Nelder and Mead (1965)

$p_{\mathrm{r}}, p_{\mathrm{e}}, p_{\text {out }}$, and $p_{\text {in }}$ are the points generated by the reflection, expansion, outside contraction, and inside contraction, respectively

\subsection{Adopted and enhanced constitutive model}

The elasto-viscoplastic model "ANICREEP" proposed by Yin et al. (2010a; 2011a; 2015b) was adopted. Based on the overstress theory, the total strain rate is additively composed of the elastic strain rates and viscoplastic strain rates:

$$
\dot{\boldsymbol{\varepsilon}}_{i j}=\dot{\boldsymbol{\varepsilon}}_{i j}^{\mathrm{e}}+\dot{\boldsymbol{\varepsilon}}_{i j}^{\mathrm{vp}},
$$

where $\dot{\boldsymbol{\varepsilon}}_{i j}$ denotes the $(i, j)$ component of the total strain rate tensor, and the superscripts e and vp stand for the elastic and the viscoplastic components, respectively. The elastic behavior in the proposed model is assumed to be isotropic, as in the modified Cam clay model. For the convenience of parameter determination, the viscoplastic strain-rate $\dot{\boldsymbol{\varepsilon}}_{i j}^{\mathrm{vp}}$ is expressed as

$$
\dot{\boldsymbol{\varepsilon}}_{i j}^{\mathrm{vp}}=\frac{C_{\alpha \mathrm{e}}\left(M_{\mathrm{c}}^{2}-\alpha_{K 0}^{2}\right)}{\tau\left(1+e_{0}\right)\left(M_{\mathrm{c}}^{2}-\eta_{K 0}^{2}\right)}\left(\frac{p_{\mathrm{m}}^{\mathrm{d}}}{p_{\mathrm{m}}^{\mathrm{r}}}\right)^{\beta} \frac{\partial f_{\mathrm{d}}}{\partial \boldsymbol{\sigma}_{i j}^{\prime}},
$$

where $\boldsymbol{\sigma}_{i j}^{\prime}$ is the stress tensor; $e_{0}$ is the initial void ratio; $\beta=C_{\alpha e} /(\lambda-\kappa) ; \lambda$ is the slope of compression line, $\kappa$ is the slope of the swelling line; $C_{\alpha \mathrm{e}}$ is the coefficient of secondary consolidation; $\tau$ is the reference time taken equal to the duration of each load increment ( $\tau=24 \mathrm{~h}$ for a conventional oedometer test); $p_{\mathrm{m}}^{\mathrm{d}}$ is the size of the dynamic loading surface and $p_{\mathrm{m}}^{\mathrm{r}}$ is the size of the reference yield surface. The dynamic loading surface $f_{\mathrm{d}}$ is treated as a viscoplastic potential function; $M_{\mathrm{c}}$ is the slope of the critical state line in the $p^{\prime}-q$ plane in compression ( $p^{\prime}$ is the mean effective stress, and $q$ is the deviatoric stress); $\alpha_{K 0}$ is the initial anisotropy of clay; $\eta_{K 0}$ is the stress ratio under $K_{0}$-consolidation, and $K_{0}$ is the coefficient of lateral pressure.

The reference surface equation can be expressed in a general stress space as

$$
f_{\mathrm{r}}=\frac{\frac{3}{2}\left(\boldsymbol{\sigma}_{\mathrm{d}}^{\prime \mathrm{r}}-p^{\prime \mathrm{r}} \boldsymbol{\alpha}_{\mathrm{d}}\right):\left(\boldsymbol{\sigma}_{\mathrm{d}}^{\prime \mathrm{r}}-p^{\prime \mathrm{r}} \boldsymbol{\alpha}_{\mathrm{d}}\right)}{\left(M^{2}-\frac{3}{2} \boldsymbol{\alpha}_{\mathrm{d}}: \boldsymbol{\alpha}_{\mathrm{d}}\right) p^{\prime \mathrm{r}}}+p^{\prime \mathrm{r}}-p_{\mathrm{m}}^{\mathrm{r}}=0,
$$

where $\sigma_{\mathrm{d}}^{\prime \mathrm{r}}$ and $p^{\prime r}$ are the reference deviatoric stress tensor and the reference mean effective stress, respectively (see point $A$ in Fig. 2, in $p^{\prime}-q$ space), and $\boldsymbol{\alpha}_{\mathrm{d}}$ is the deviatoric fabric tensor (Yin et al., 2010a). Corresponding to the current stress state (point $B$ in Fig. 2), a dynamic loading surface $f_{\mathrm{d}}$ is defined, which has an elliptical shape identical to the reference yield surface, but a different size $p_{\mathrm{m}}^{\mathrm{d}}$.

To interpolate $M$ between its values $M_{\mathrm{c}}$ (for compression) and $M_{\mathrm{e}}$ (for extension), according to Sheng et al. (2000) a modification of $M$ by means of the lode angle $q$ is assumed:

$$
M=M_{\mathrm{c}}\left[\frac{2 c^{4}}{1+c^{4}+\left(1-c^{4}\right) \sin (3 \theta)}\right]^{\frac{1}{4}}
$$

with $\frac{-\pi}{6} \leq \theta=\frac{1}{3} \arcsin \left(\frac{-3 \sqrt{3} \bar{J}_{3}}{2 \bar{J}_{2}^{3 / 2}}\right) \leq \frac{\pi}{6}, \bar{J}_{2}=\frac{1}{2} \overline{\boldsymbol{s}}_{i j}: \overline{\boldsymbol{s}}_{i j}$, $\bar{J}_{3}=\overline{\boldsymbol{s}}_{i j} \overline{\boldsymbol{s}}_{j k} \overline{\boldsymbol{s}}_{k i} / 3, \quad \overline{\boldsymbol{s}}_{i j}=\boldsymbol{\sigma}_{\mathrm{d}}-p^{\prime} \boldsymbol{\alpha}_{\mathrm{d}}, \quad$ where $c=\left(3-\sin \phi_{\mathrm{c}}\right) /$ $\left(3+\sin \phi_{c}\right)$ according to the Mohr-Coulomb yield criterion, and $\phi_{\mathrm{c}}$ is the friction angle.

The rotational hardening law that describes the development of anisotropy caused by viscoplastic strains is expressed as

$$
\mathrm{d} \boldsymbol{\alpha}_{\mathrm{d}}=\omega\left[\left(\frac{3 \sigma_{\mathrm{d}}}{4 p^{\prime}}-\boldsymbol{\alpha}_{\mathrm{d}}\right)\left\langle\mathrm{d} \boldsymbol{\varepsilon}_{\mathrm{v}}^{\mathrm{vp}}\right\rangle+\omega_{\mathrm{d}}\left(\frac{\boldsymbol{\sigma}_{\mathrm{d}}}{3 p^{\prime}}-\boldsymbol{\alpha}_{\mathrm{d}}\right) \mathrm{d} \boldsymbol{\varepsilon}_{\mathrm{d}}^{\mathrm{vp}}\right],
$$

where $\left\langle\mathrm{d} \boldsymbol{\varepsilon}_{\mathrm{v}}^{\mathrm{vp}}\right\rangle=0$ for $\mathrm{d} \boldsymbol{\varepsilon}_{\mathrm{v}}^{\mathrm{vp}} \leq 0$ and $\left\langle\mathrm{d} \boldsymbol{\varepsilon}_{\mathrm{v}}^{\mathrm{vp}}\right\rangle=\mathrm{d} \boldsymbol{\varepsilon}_{\mathrm{v}}^{\mathrm{vp}}$ for $\mathrm{d} \varepsilon_{\mathrm{v}}^{\mathrm{vp}}>0$. The soil constants $\omega$ and $\omega_{\mathrm{d}}$ control the 
effect of viscoplastic strains on the rotation of the ellipsoidal surface, and can be obtained by

$$
\begin{aligned}
& \omega_{\mathrm{d}}=\frac{3\left(4 M_{\mathrm{c}}^{2}-4 \eta_{K 0}^{2}-3 \eta_{K 0}\right)}{8\left(\eta_{K 0}^{2}+2 \eta_{K 0}-M_{\mathrm{c}}^{2}\right)} \\
& \omega=\frac{1+e_{0}}{\lambda_{\mathrm{i}}-\kappa} \ln \frac{10 M_{\mathrm{c}}^{2}-2 \alpha_{K 0} \omega_{\mathrm{d}}}{M_{\mathrm{c}}^{2}-2 \alpha_{K 0} \omega_{\mathrm{d}}}
\end{aligned}
$$

with

$$
\eta_{K 0}=\frac{3 M_{\mathrm{c}}}{6-M_{\mathrm{c}}}, \quad \alpha_{K 0}=\eta_{K 0}-\frac{M_{\mathrm{c}}^{2}-\eta_{K 0}^{2}}{3} .
$$
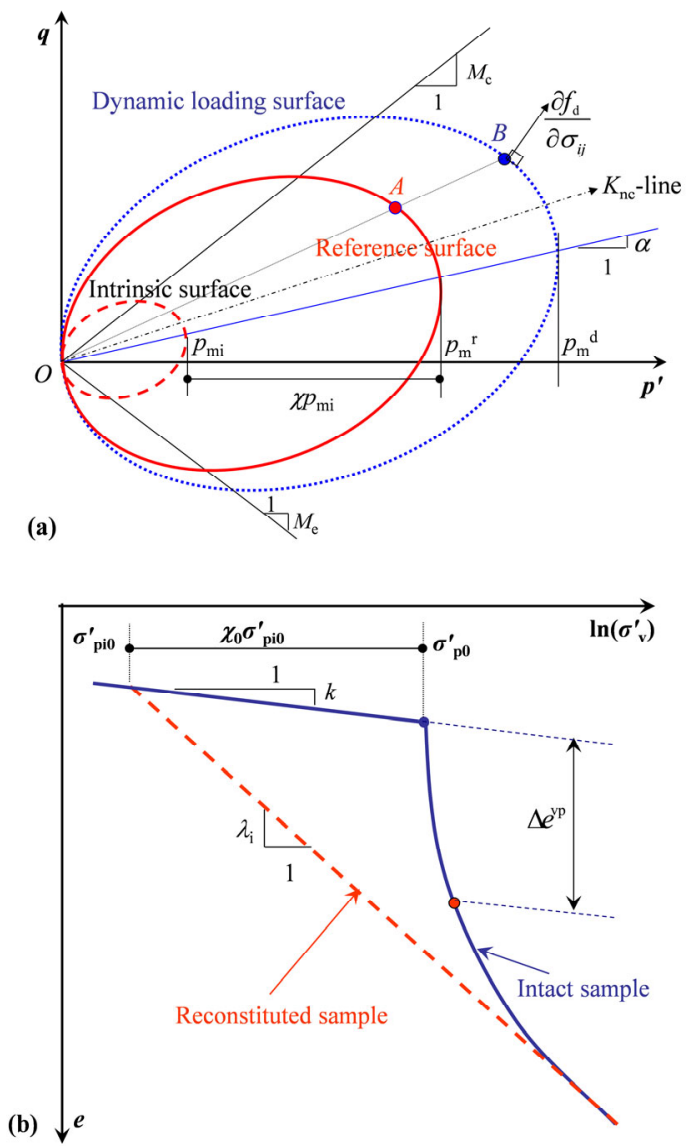

Fig. 2 Definitions for the model in $p^{\prime}-q$ space (a) and 1D compression condition (b) (Yin et al., 2011a)

$\sigma_{\mathrm{p} 0}^{\prime}$ and $\sigma_{\mathrm{p} i 0}^{\prime}$ are the pre-consolidated pressures for the natural sample and reconstituted sample, respectively; $K_{\mathrm{nc}}$ is the coefficient of lateral pressure for normally consolidated clay

The size of the reference yield surface $p_{\mathrm{m}}^{\mathrm{r}}$ can be expressed by the size of the intrinsic surface $p_{\mathrm{mi}}$ and the amount of bonding $\chi$ as

$$
p_{\mathrm{m}}^{\mathrm{r}}=(1+\chi) p_{\mathrm{mi}}
$$

with the hardening law of the intrinsic surface,

$$
\mathrm{d} p_{\mathrm{mi}}=p_{\mathrm{mi}} \frac{1+e_{0}}{\lambda_{\mathrm{i}}-\kappa} \mathrm{d} \varepsilon_{\mathrm{v}}^{\mathrm{vp}}
$$

and the bond degradation law,

$$
\mathrm{d} \chi=-\chi \xi\left(\left|\mathrm{d} \varepsilon_{\mathrm{v}}^{\mathrm{vp}}\right|+\xi_{\mathrm{d}} \mathrm{d} \boldsymbol{\varepsilon}_{\mathrm{d}}^{\mathrm{vp}}\right)
$$

where the initial value of $\chi_{0}=S_{\mathrm{t}}-1$ can be obtained using the sensitivity $S_{\mathrm{t}}$ as input; the soil constants $\xi$ and $\xi_{\mathrm{d}}$ control the effect of viscoplastic volumetric and deviatoric strains, respectively, in destroying the bonds.

Due to its natural deposition, the soil exhibits naturally inherent anisotropy of elasticity (Yin and Chang, 2009; Chang and Yin, 2010; Yin et al., 2010a; 2011a; 2013). The anisotropic elastic behavior is considered in this model by the following matrix of elastic stiffness:

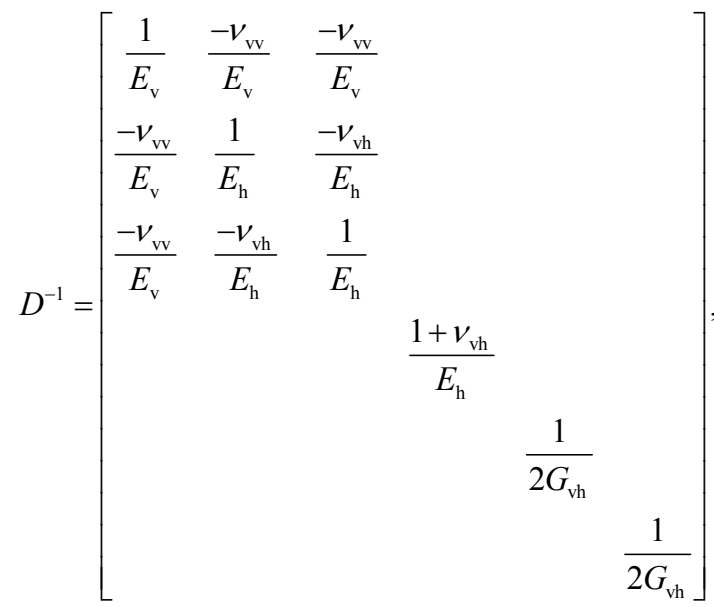

with $n=E_{\mathrm{h}} / E_{\mathrm{v}}=0.5, \quad v_{\mathrm{vv}}=v_{\mathrm{vh}} / \sqrt{n}, \quad$ and $\quad 2 G_{\mathrm{vh}}=$ $\sqrt{n} E_{\mathrm{v}} /\left(1+v_{\mathrm{vh}}\right)$, where $E_{\mathrm{v}}$ and $E_{\mathrm{h}}$ is vertical and horizontal Young's modulus, $v_{\mathrm{vv}}$ and $v_{\mathrm{vh}}$ is vertical and horizontal Poisson's ratio, respectively, and $G_{\mathrm{vh}}$ is the shear modulus.

Input parameters of the model are summarized in Table 1 with their recommended methods of determination (Yin et al., 2011a).

Overall, the recently developed 'ANICREEP' model can capture the main features of natural sensitive clay, such as soil viscosity, anisotropy, and destructuration. At the same time, the reduction of the 
apparent secondary compression coefficient through inter-particle debonding can be reproduced. The model's predictive ability has been validated for various soft sensitive clays (Yin et al., 2010a; 2011a; Karstunen and Yin, 2010; Zhu et al., 2014). Therefore, this model was adopted in this study.

\subsection{Selected clays and tests}

Wenzhou clay deposit is a marine clay characterized as slightly organic and highly plastic. A relatively homogeneous layer of Wenzhou clay from 10.5 to $11.5 \mathrm{~m}$ deep was selected for this study. Some common physical properties are listed in Table 2. Intensive laboratory tests were carried out along various stress paths, focusing on the rate-dependent mechanical properties of Wenzhou clay (Yin et al., 2015b).

To keep the same condition as the standard for soil characterization, the tests selected as the objective for this study were three conventional undrained triaxial tests on $K_{0}$-consolidated Wenzhou clay under different confining stresses. The $K_{0}$-consolidation was performed within 2 days up to a vertical stress of $75 \mathrm{kPa}$, another 2 days up to $150 \mathrm{kPa}$ and finally another 2 days up to $300 \mathrm{kPa}$. For the undrained triaxial shearing stage, a strain rate of $2 \% / \mathrm{h}$ was applied during tests according to the ASTM (2004) standard and was also adopted in the simulations. The results of these undrained triaxial tests with their $K_{0}$-consolidation curves are shown in Fig. 3.

Table 1 State parameters and soil constants of an elastic viscoplastic model

\begin{tabular}{|c|c|c|c|c|}
\hline Group & Parameter & Def & inition & Determination \\
\hline \multirow{6}{*}{$\begin{array}{l}\text { Modified Cam } \\
\text { clay parameters }\end{array}$} & $\sigma_{\mathrm{p} 0}^{\prime \mathrm{r}}$ & \multicolumn{2}{|c|}{$\begin{array}{l}\text { Initial reference preconsolidation } \\
\text { pressure }\end{array}$} & $\begin{array}{l}\text { From a selected oedometer test whose loading- } \\
\text { rate is used as reference strain-rate }\end{array}$ \\
\hline & $e_{0}$ & \multicolumn{2}{|c|}{ Initial void ratio (state parameter) } & From oedometer test \\
\hline & $v$ & \multicolumn{2}{|c|}{ Poisson's ratio } & $\begin{array}{l}\text { From initial part of stress-strain curve (typically } \\
\text { varying from } 0.15 \text { to } 0.35 \text { ) }\end{array}$ \\
\hline & $\kappa$ & \multicolumn{2}{|c|}{ Slope of the swelling line } & From 1D or isotropic consolidation test \\
\hline & $\lambda_{\mathrm{i}}$ & \multicolumn{2}{|c|}{ Intrinsic slope of the compression line } & From 1D or isotropic consolidation test \\
\hline & $M$ & \multicolumn{2}{|c|}{ Slope of the critical state line } & From triaxial shear test \\
\hline \multirow[t]{2}{*}{$\begin{array}{l}\text { Anisotropy } \\
\text { parameters }\end{array}$} & $\alpha_{0}$ & \multicolumn{2}{|c|}{$\begin{array}{l}\text { Initial anisotropy (state parameter for } \\
\text { calculating initial components of the } \\
\text { fabric tensor) }\end{array}$} & For $K_{0}$-consolidated samples by $\mathrm{P}[1]^{\S}$ \\
\hline & $\omega$ & \multicolumn{2}{|c|}{ Absolute rate of yield surface rotation } & Calculated by Eq. (7) \\
\hline \multirow{3}{*}{$\begin{array}{l}\text { Destructuration } \\
\text { parameters }\end{array}$} & $\chi_{0}$ & \multirow{3}{*}{\multicolumn{2}{|c|}{$\begin{array}{l}\text { Initial bonding ratio } \\
\text { Absolute rate of bond degradation } \\
\text { Relative rate of bond degradation }\end{array}$}} & From shear vane test or oedometer test by $\mathrm{P}[2]^{\S}$ \\
\hline & $\xi$ & & & From consolidation tests with two different stress \\
\hline & $\xi_{\mathrm{d}}$ & & & $\begin{array}{l}\text { ratios } \eta=q / p^{\prime} \text {, e.g., oedometer test and isotropic } \\
\text { consolidation test, calculated by } \mathrm{P}[3]^{\S}\end{array}$ \\
\hline $\begin{array}{c}\text { Viscosity } \\
\text { parameters }\end{array}$ & $C_{\text {aei }}$ & \multicolumn{2}{|c|}{$\begin{array}{l}\text { Secondary compression coefficient for } \\
\text { reconstituted clay }\end{array}$} & From 24 h oedometer test on remoulded sample \\
\hline \multirow{2}{*}{$\begin{array}{l}\text { Hydraulic } \\
\text { parameters }\end{array}$} & $k_{\mathrm{v} 0}, k_{\mathrm{h} 0}$ & \multicolumn{2}{|c|}{$\begin{array}{l}\text { Initial vertical and horizontal } \\
\text { permeability }\end{array}$} & From oedometer tests \\
\hline & $c_{\mathrm{k}}$ & \multicolumn{2}{|c|}{ Permeability coefficient } & From curve $e-\log k$ \\
\hline \multicolumn{5}{|c|}{$\S[\mathrm{P} 1]: \alpha_{0}=\alpha_{K 0}=\eta_{K 0}-\frac{M^{2}-\eta_{K 0}^{2}}{3}$ with $\eta_{K 0}=\frac{3 M}{6-M} ;[\mathrm{P} 2]: \chi_{0}=S_{\mathrm{t}}-1$ (from shear vane test), or $\chi_{0}=\sigma_{\mathrm{p} 0}^{\prime} / \sigma_{\mathrm{p} i 0}^{\prime}-1 \quad($ from } \\
\hline \multicolumn{3}{|c|}{ oedometer tests); [P3]: $\xi+\xi \cdot \xi_{\mathrm{d}} \frac{2(\eta-\alpha)}{M^{2}-\eta^{2}}=\frac{-\left(1+e_{0}\right)}{e^{\mathrm{vp}}} \ln$} & $\frac{\sigma_{\mathrm{f}}^{\prime}}{\chi_{0} \sigma_{\mathrm{vi} 0}^{\prime} \exp \frac{e^{\mathrm{vp}}}{\lambda_{1}-\kappa}}-\frac{1}{\chi_{0}}$ & (viscoplastic void ratio $e^{\mathrm{vp}}$ corresponding to $\sigma_{\mathrm{v}}^{\prime}$ ) \\
\hline
\end{tabular}

Table 2 Physical properties typical of Wenzhou marine clay and soft Shanghai clay

\begin{tabular}{ccccccccc}
\hline Clay & Depth $(\mathrm{m})$ & $\begin{array}{c}\text { Density, } \gamma \\
\left(\mathrm{kN} / \mathrm{m}^{3}\right)\end{array}$ & $e_{0}$ & $\begin{array}{c}\text { Water content, } \\
w(\%)\end{array}$ & $\begin{array}{c}\text { Liquid limit, } \\
w_{\mathrm{L}}(\%)\end{array}$ & $\begin{array}{c}\text { Plastic limit, } \\
w_{\mathrm{P}}(\%)\end{array}$ & $\sigma_{\mathrm{p} 0}^{\prime}(\mathrm{kPa})$ & $\sigma_{\mathrm{v} 0}^{\prime}(\mathrm{kPa})$ \\
\hline Wenzhou & $10.5-11.5$ & 15.5 & 1.895 & 67.5 & 63.4 & 27.6 & 81.3 & 75.4 \\
Shanghai & 10 & 17.7 & 1.402 & 51.8 & 44.2 & 22.4 & 110.5 & 68.6 \\
\hline
\end{tabular}



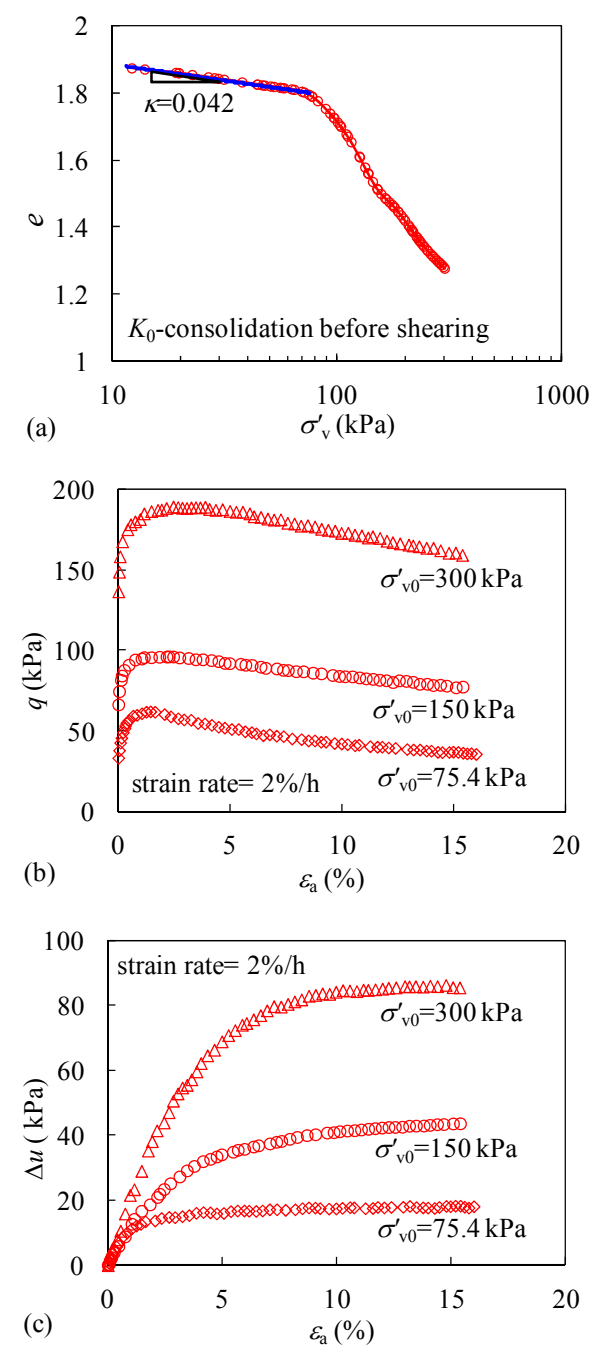

Fig. 3 Triaxial test results on Wenzhou clay: (a) $K_{0}$ consolidation stage; (b) axial strain-deviatoric stress; (c) axial strain-excess pore pressure

Based on selected tests, some parameters were directly obtained: $M=1.23$ and $\kappa=0.042$. For a sensitive clay, creep and destructuration related parameters are of significant importance, not only for constitutive modeling, but also in practice (e.g., directly relating to the secondary compression coefficient and sensitivity). They usually require more experimental data to be determined. Therefore, it would be of great benefit to develop a procedure which allows these parameters to be identified based on only conventional tests on intact samples. To focus on identifying creep and destructuration parameters (secondary compression coefficient corresponding to the reconstituted clay $C_{\text {aei }}$, initial bonding $\chi_{0}$, destructuration constants $\xi$ and $\xi_{\mathrm{d}}$ ), the intrinsic compression index $\lambda_{\mathrm{i}}=0.197$ (corresponding to the reconstituted clay) was taken from $C_{\mathrm{c}}=0.009\left(w_{\mathrm{L}}-13\right)$ as suggested by Biarez and Hicher (1994).

The inherent anisotropy of elastic stiffness for normally consolidated or slightly over-consolidated clays much depends on the in-situ stress state from microstructural and micromechanical points of view, with $n=\sigma_{\mathrm{h} 0} / \sigma_{\mathrm{v} 0}$ recommended by Yin et al. (2009; 2011a; 2013). Therefore, this was adopted in this paper. The Poisson's ratio usually varies from 0.15 to 0.35 for different clays, and is not sensitive to $1 \mathrm{D}$ compression and undrained triaxial behaviors. Thus, a typical value $v=0.25$ was adopted in this study.

\subsection{Proposed optimization procedure and results}

The aim of the inverse modelling procedure is to find values for the model parameters that provide the best attainable fit between model predictions and corresponding observations. Therefore, only one error function is required to be considered in this study. Thus, we considered a mono-objective framework with three different criteria:

$$
\min [\operatorname{Error}(x)]=\min \left[\begin{array}{l}
\operatorname{Error}\left(K_{0}\right) \\
\operatorname{Error}(q) \\
\operatorname{Error}(\Delta u)
\end{array}\right] .
$$

The total average error function is expressed as

$$
\operatorname{Error}(x)=\sum_{i=1}^{m}\left[l_{i} \cdot \operatorname{Error}(x)_{i}\right]
$$

where $m$ is the number of objectives; $\operatorname{Error}(x)_{i}$ is the value of error corresponding to the objective $i$ and $l_{i}$ is the weight factor with $\sum\left(l_{i}\right)=1$. The weight factor $l_{i}$ is taken to be equal to $1 / 3$ in this case, since each test plays the same important role in evaluating soil behavior. Then, the average error is taken to be equal to $\left[\operatorname{Error}(q)+\operatorname{Error}(\Delta u)+\operatorname{Error}\left(K_{0}\right)\right] / 3$, with $\operatorname{Error}(q)$, $\operatorname{Error}(\Delta u)$, and $\operatorname{Error}\left(K_{0}\right)$ representing the difference between experiments and numerical simulations based on different curves in Fig. 3 for deviatoric stress, excess pore pressure, and vertical stress in the $K_{0}$-consolidation stage, respectively.

Fig. 4 shows the identification procedure based on the successive use of two different codes: the code for the integration of the constitutive model and the 
code for the optimization process. The ANICREEP model at a single integration point level was adopted to be combined with the optimization procedure. Each initial set of individuals for the simplex algorithm is generated with ULH. The intervals of parameters given in Table 3 are much larger than those corresponding to typical values. The required initial individuals for SA is $n+1$ ( $n$ is the number of variables).

The optimization procedure described above was carried out. Since SA depends strongly on the initial sets of parameters (individuals), the way of overcoming this drawback is to carry out multiple optimizations starting from different initial sets of parameters. As suggested by Papon et al. (2012), 10 optimizations with different initial sets of parameters

Table 3 Interval of creep and destructuration related parameters of the model for optimization

\begin{tabular}{cccc}
\hline Parameter & $\begin{array}{c}\text { Minimal } \\
\text { value }\end{array}$ & $\begin{array}{c}\text { Maximal } \\
\text { value }\end{array}$ & Step \\
\hline$C_{\text {aei }}$ & 0.0001 & 0.1 & 0.0001 \\
$\chi_{0}$ & 0 & 50 & 0.5 \\
$\xi$ & 0 & 20 & 0.5 \\
$\xi_{\mathrm{d}}$ & 0 & 0.5 & 0.02 \\
\hline
\end{tabular}

generated by ULH were carried out. All individuals whose errors are lower than a reference value, are called "satisfactory". Thus, more than one optimized satisfactory set of parameters can be selected with an average error of less than $9 \%$ (Fig. 5).

These optimized satisfactory sets of parameters are plotted (dotted line in Fig. 6). All the selected parameters are located within a narrow range and different sets of parameters can result in similar errors. Thus, the coupling effect between creep and destructuration is apparent and cannot be ignored. The evidence confirms that the coupling effect makes it difficult to identify parameters in the traditional way. The sets of parameters with minimum average error were selected and are summarized in Table 4.

Table 4 Optimal sets of parameters with objective error

\begin{tabular}{crrrrc}
\hline \multirow{2}{*}{ Clay } & \multicolumn{4}{c}{ Optimal parameter } & $\begin{array}{c}\text { Objective } \\
\text { error (\%) }\end{array}$ \\
\cline { 2 - 5 } & $C_{\text {aei }}$ & \multicolumn{1}{c}{$\chi_{0}$} & \multicolumn{1}{c}{$\xi$} & $\xi_{\mathrm{d}}$ & \\
\hline Wenzhou & 0.0032 & 8.5 & 13.0 & 0.24 & 8.85 \\
Shanghai & 0.0025 & 4.0 & 9.5 & 0.45 & 17.21 \\
\hline
\end{tabular}

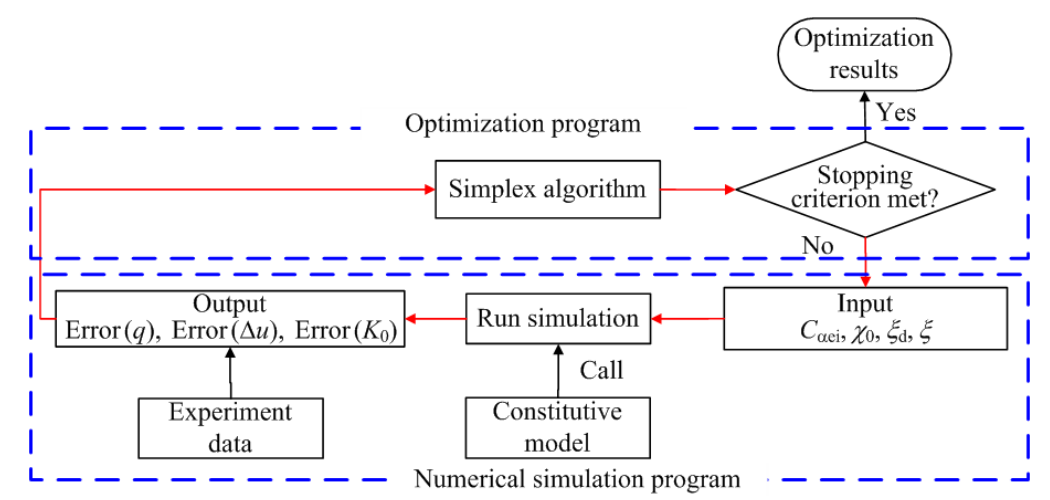

Fig. 4 Mono-objective optimization procedure

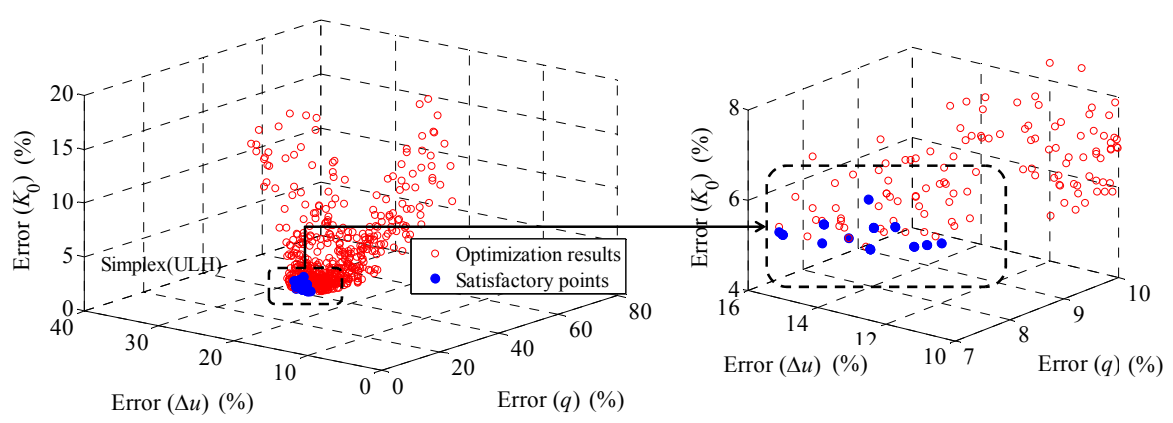

Fig. 5 Distribution of "satisfactory" solutions generated during optimization of the SA 


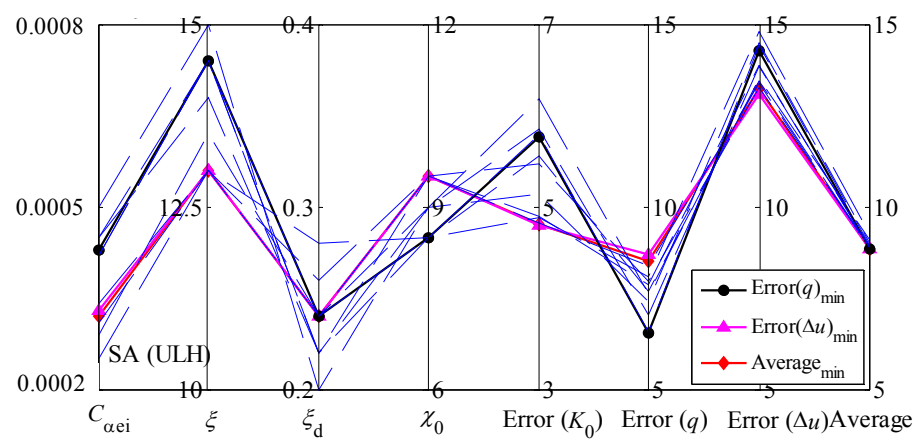

Fig. 6 Distribution of satisfactory solutions obtained by the SA

The computational time is also a criterion to evaluate the performance of SA optimization. The problem is that the number of attempts to detect the optimum solution by using SA in each optimization depends on the initial sets of individuals. In this study, the time for each optimization varies by less than $1 \mathrm{~h}$. From this point of view, this shows that the SA is highly efficient in identifying creep and destructuration related parameters.

\subsection{Validation by other tests on the same clay}

\subsubsection{Validation based on experimental measurements}

Additional test data on the same Wenzhou marine clay (Zeng, 2010; Yin et al., 2015b) were used to validate the optimal set of parameters. The measured value of initial bonding $\chi_{0}$ defined as $\chi_{0}=\sigma_{\mathrm{p} 0}^{\prime} / \sigma_{\mathrm{pi} 0}^{\prime}-1$ (Fig. 1b) for Wenzhou marine clay was equal to about 9.0 (Fig. 7). From the optimization analysis, $\chi_{0}$ was obtained as equal to 8.5 by SA. This is close to the value obtained by direct measurement. For this specific parameter, the SA with ULH seems suitable for identifying creep and destructuration parameters.

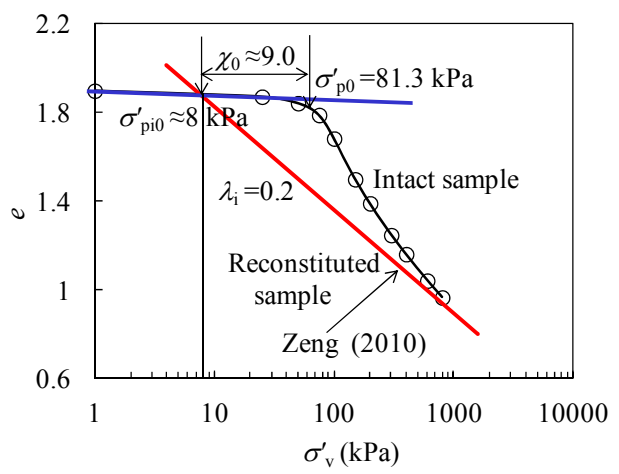

Fig. 7 1D compression results of intact and reconstituted Wenzhou clay
Fig. 8 shows the relationship between $C_{\alpha \mathrm{e}}$ and $\lambda$ for Wenzhou clay by Yin et al. (2015b) with the average ratio of $C_{a \mathrm{a}} / \lambda=0.0256$. The optimized values of $C_{\text {aei }}$ with the given value of $\lambda_{\mathrm{i}}=0.197$ are also plotted in Fig. 8. All the values obtained from optimization are within a reasonable range compared to those from the experiment. Therefore, the SA method appears suitable for identifying parameters related to creep and destructuration.

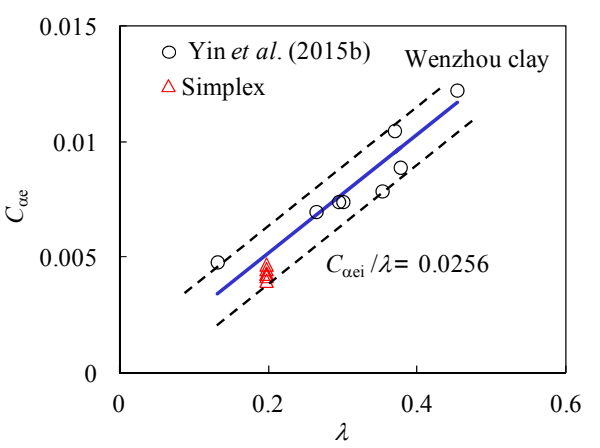

Fig. 8 Relationship between $C_{a \mathrm{e}}$ and $\lambda$ for Wenzhou marine clay

The ANICREEP model adopted in this study has one parameter ' $C_{\mathrm{ae}}$ ' concerning the viscosity of soils. In the case that all other parameters are fixed, one $C_{\text {ae }}$ controls not only one stress-strain relationship (e.g., a unique $q-\varepsilon_{\mathrm{a}}$ curve, where $\varepsilon_{\mathrm{a}}$ is axial strain) for the test at a given strain-rate, but also the rate-dependency of shear strength for tests at various strain-rates. Thus, for identifying this parameter, the simplest requirement is only one undrained triaxial test under a given strain-rate.

\subsubsection{Validation based on test simulations}

1D multi-staged constant rate of strain (CRS) tests, undrained triaxial tests in compression and 
extension, and undrained creep tests on the same Wenzhou clay (Yin et al., 2015b) were simulated by the enhanced model with the optimized parameters shown in Table 4.

One multi-staged CRS oedometer test with strain rates varying between $0.2 \% / \mathrm{h}$ and $20 \% / \mathrm{h}$ was simulated and compared to experimental results (Fig. 9). A good agreement between experiments and simulations was achieved. This demonstrates firstly that the enhanced model can predict 1D rate-dependent behavior of Wenzhou marine clay, and secondly, that the soil parameters optimized by SA are suitable.

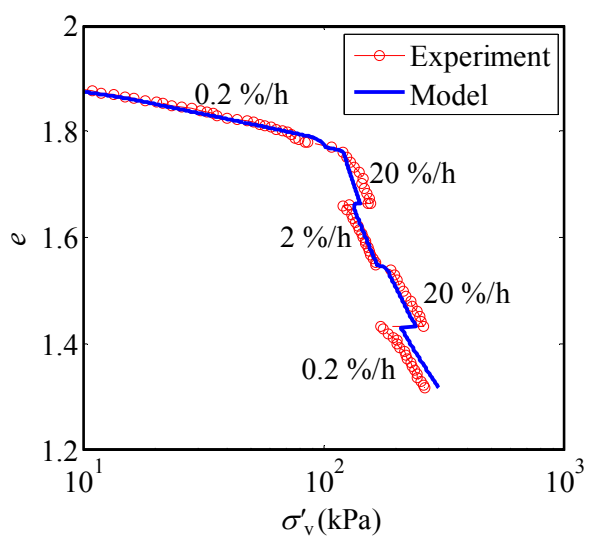

Fig. 9 Comparisons between simulated and measured results of a CRS oedometer test with axial strain-rate varying between $0.2 \% / \mathrm{h}$ and $20 \% / \mathrm{h}$

In terms of 3D CRS tests, the simulations of objective tests and additional extension tests are presented in Fig. 10. The differences between the different simulations were very small and the overall quality of the simulations was satisfactory. This indicates that the simplex optimization is highly capable of finding the best solution. Moreover, the enhanced model can reproduce the time-dependent and destructuration behaviors of soft clay.

Then, three sets of undrained triaxial tests in compression and extension on $K_{0}$-consolidated samples under vertical effective stresses $\left(\sigma_{\mathrm{v} 0}^{\prime}=75.4\right)$ at strain-rates of $0.2,2$, and $20 \% / \mathrm{h}$ were simulated. Fig. 11 shows comparisons between the predicted and measured results for deviatoric stress vs. axial strain and the effective stress path. Good agreement between experiments and simulations was generally achieved by the enhanced model with the set parameters optimized by the SA method.
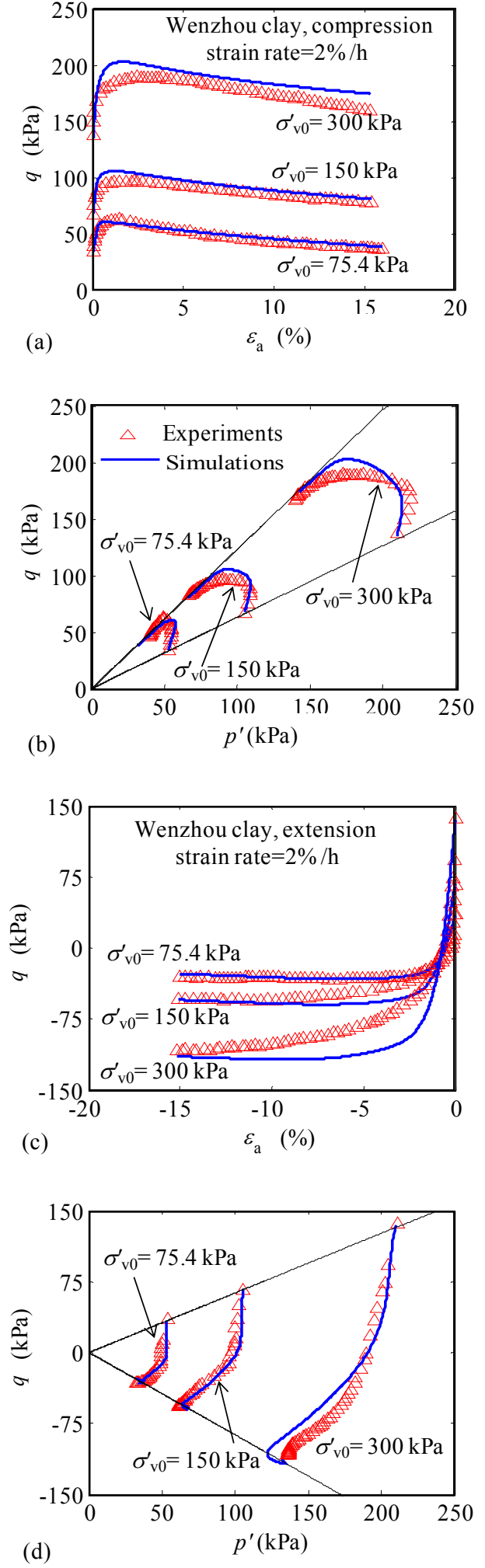

Fig. 10 Comparisons between simulated and measured results of objective tests in compression (a and b) and corresponding extension (c and $d$ ) at initial vertical stresses of 75.4, 150, and $300 \mathrm{kPa}$ 


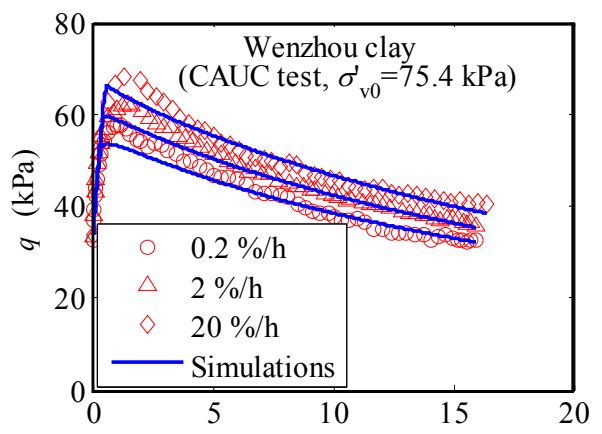

(a)
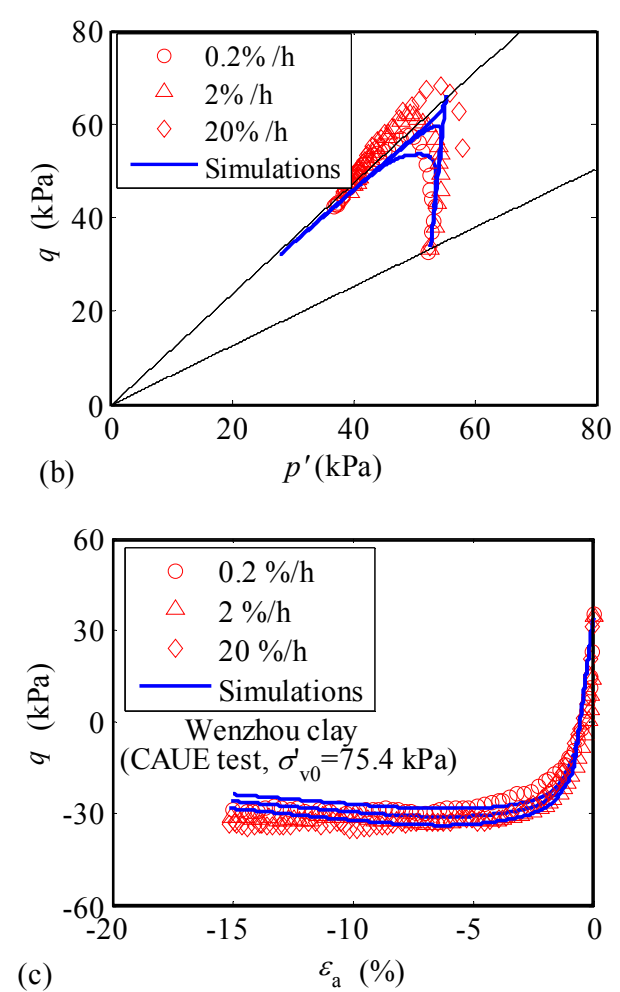

(c)

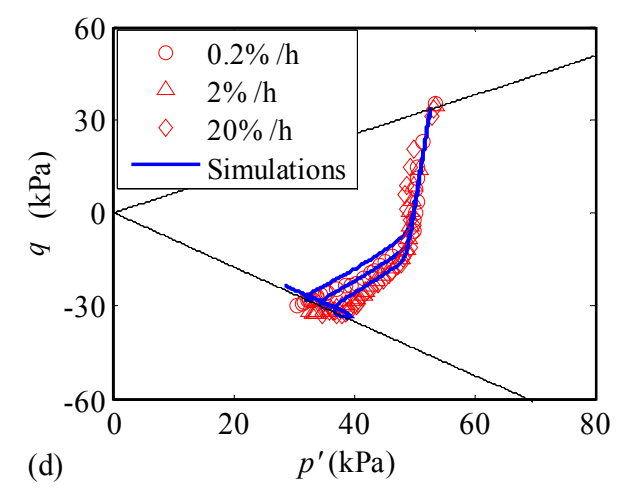

Fig. 11 Comparisons between simulated and measured results of undrained triaxial CRS tests in compression (a and b) and extension (c and $d$ ) at an initial vertical stress of $75.4 \mathrm{kPa}$

CAUC: anisotropic consolidation undrained compression; CAUE: anisotropic consolidation undrained extension

\section{Application to soft Shanghai clay}

According to Huang et al. (2011), undisturbed samples of Shanghai clay were taken at depths of $10 \mathrm{~m}$, with in situ horizontal consolidation stress $\sigma_{\mathrm{hc}}^{\prime}=41 \mathrm{kPa}$ and vertical consolidation stress $\sigma_{\mathrm{vc}}^{\prime}=$ $68.6 \mathrm{kPa}$. The initial mean effective stress $p_{\mathrm{c}}^{\prime}$ was determined to be $50.3 \mathrm{kPa}$. Some physical properties of Shanghai soft clay are presented in Table 2.

Two available undrained compression tests performed on the $K_{0}$-consolidated consolidated Shanghai clay were selected as the objective to identify the creep and destructuration related parameters (Fig. 12). Based on the results, the slope of the critical state line was measured with $M_{\mathrm{c}}=1.28$. The swelling index $\kappa=0.041$ was obtained from the 1D consolidation test. The intrinsic compression index $\lambda_{\mathrm{i}}=0.122$ was estimated by the equation of Biarez and Hicher (1994). The typical value of Poisson's ratio $v=0.25$ was assumed.
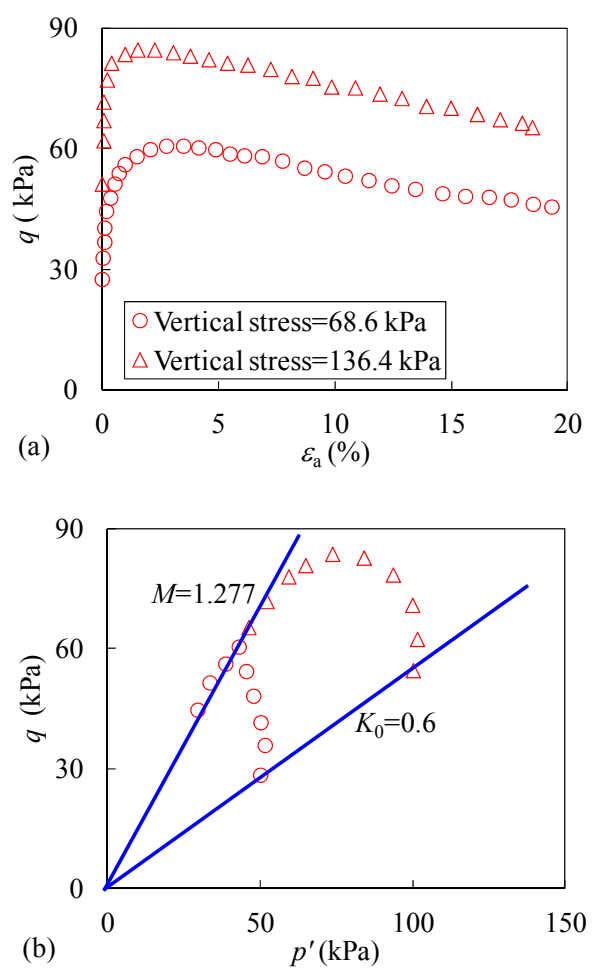

Fig. 12 Triaxial test results on Shanghai clay: (a) axial strain-deviatoric stress; (b) stress path

The same optimization procedure was conducted using simplex on Shanghai clay. The optimization results are shown in Table 4 . The values of 
$C_{\text {aei }}$ and $\chi_{0}$ are in agreement with previous data on Shanghai clay published by Huang et al. (2011) and Zhu et al. (2013). Using the optimal parameters, the objective tests were simulated (Fig. 13). The simulations demonstrate that the SA has the ability to find a better set of parameters and the enhanced model performs well in describing the creep and destructuration behaviors of Shanghai clay. For further validation, the tests performed on the isotropically consolidated soft Shanghai clay under different confining pressures were simulated using the optimal parameters given by simplex. Comparisons between simulated and experimental results (Fig. 14) indicate that the optimization procedure combined with the SA and the appropriate creep model is efficient and reliable in identifying creep and destructuration related parameters.
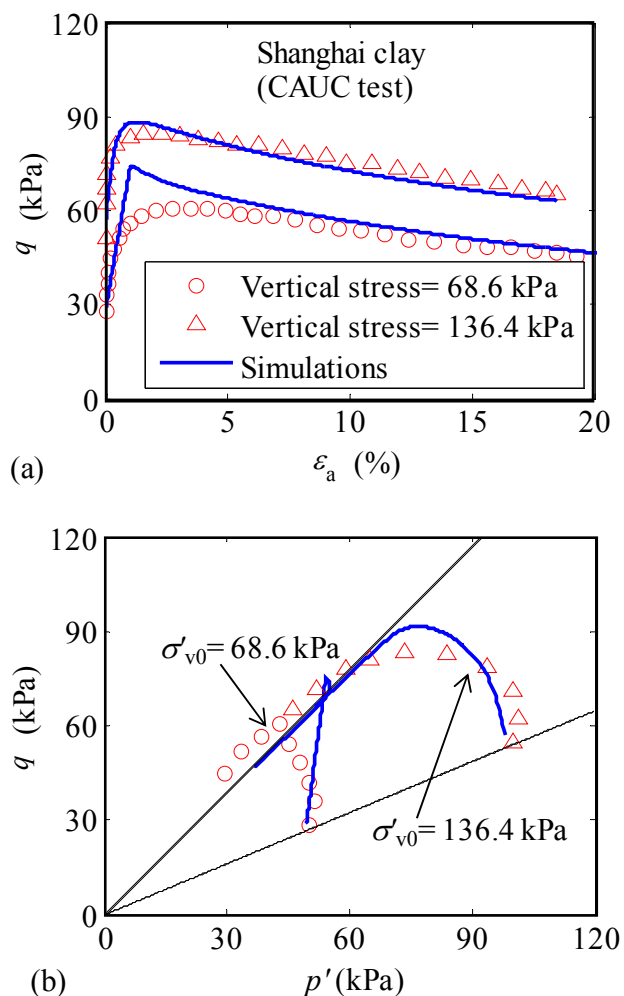

Fig. 13 Simulations of objective tests of Shanghai clay using optimal parameters

\section{Conclusions}

An efficient optimization procedure for identifying creep and destructuration related soil parameters using standard experimental tests has been
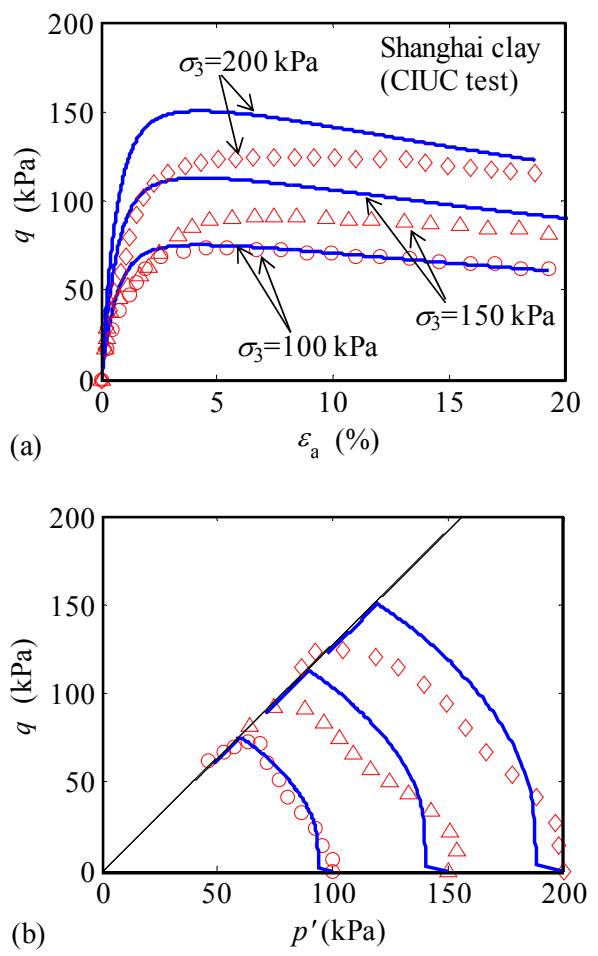

Fig. 14 Simulated results of tests on isotropically consolidated Shanghai clay with different confining pressures CIUC: isotropic consolidation undrained compression

proposed. A newly developed elastic viscoplastic model accounting for creep and destructuration has been enhanced and adopted for modeling the timedependent stress-strain behavior of soft clay.

The optimization procedure was considered as a mono-objective problem using an SA with a random initialization method. Three conventional undrained triaxial compression tests on Wenzhou clay were selected as the objective. The set of parameters with minimum objective error was selected as the optimal values. The optimal secondary compression coefficient and soil sensitivity were first validated by comparison with the experimental measurements. The optimal parameters were then validated by simulating other tests on the same Wenzhou clay. Comparisons between simulated and experimental results demonstrate that the proposed optimization procedure is efficient and reliable. Finally, the proposed procedure was applied to soft Shanghai clay to evaluate its capability in identifying creep and destructuration related parameters. The results demonstrate that the proposed optimization procedure can be recommended for use in engineering practice. 
Future work may include the application of the advanced optimization methods, combined with advanced constitutive models, to field tests or measurements.

\section{Acknowledgments}

The authors thank Prof. Li-zhong WANG (Institute of Geotechnical Engineering, Zhejiang University) for providing the testing data.

\section{References}

ASTM (American Society for Testing and Materials), 2004. Annual Book of ASTM Standards. ASTM, Philadelphia, PA, USA.

Biarez, J., Hicher, P.Y., 1994. Elementary mechanics of soil behaviour: saturated remoulded soils. AA Balkema, Rotterdam, the Netherlands.

Calvello, M., Finno, R.J., 2004. Selecting parameters to optimize in model calibration by inverse analysis. Computers and Geotechnics, 31(5):410-424. http://dx.doi.org/10.1016/j.compgeo.2004.03.004

Chang, C.S., Yin, Z.Y., 2010. Micromechanical modeling for inherent anisotropy in granular materials. Journal of Engineering Mechanics, 136(7):830-839. http://dx.doi.org/10.1061/(ASCE)EM.1943-7889.0000125

Dano, C., Hicher, P.Y., Rangeard, D., et al., 2007. Interpretation of dilatometer tests in a heavy oil reservoir. International Journal for Numerical and Analytical Methods in Geomechanics, 31(10):1197-1215. http://dx.doi.org/10.1002/nag.583

Huang, M., Liu, Y., Sheng, D., 2011. Simulation of yielding and stress-stain behavior of Shanghai soft clay. Computers and Geotechnics, 38(3):341-353. http://dx.doi.org/10.1016/j.compgeo.2010.12.005

Karstunen, M., Yin, Z.Y., 2010. Modelling time-dependent behaviour of Murro test embankment. Géotechnique, 60(10): 735-749. http://dx.doi.org/10.1680/geot.8.P.027

Lagarias, J.C., Reeds, J.A., Wright, M.H., et al., 1998. Convergence properties of the Nelder-Mead simplex method in low dimensions. SIAM Journal on Optimization, 9(1):112-147. http://dx.doi.org/10.1137/S1052623496303470

Lecampion, B., Constantinescu, A., Nguyen Minh, D., 2002. Parameter identification for lined tunnels in a viscoplastic medium. International Journal for Numerical and Analytical Methods in Geomechanics, 26(12):1191-1211. http://dx.doi.org/10.1002/nag.241

Leroueil, S., Vaughan, P.R., 1990. The general and congruent effects of structure in natural soils and weak rocks. Géotechnique, 40(3):467-488. http://dx.doi.org/10.1680/geot.1990.40.3.467

Levasseur, S., Malécot, Y., Boulon, M., et al., 2008. Soil parameter identification using a genetic algorithm. International Journal for Numerical and Analytical Meth- ods in Geomechanics, 32(2):189-213.

http://dx.doi.org/10.1002/nag.614

McKay, M.D., Beckman, R.J., Conover, W.J., 1979. Comparison of three methods for selecting values of input variables in the analysis of output from a computer code. Technometrics, 21(2):239-245. http://dx.doi.org/10.1080/00401706.1979.10489755

Nelder, J.A., Mead, R., 1965. A simplex method for function minimization. The Computer Journal, 7(4):308-313. http://dx.doi.org/10.1093/comjnl/7.4.308

Papon, A., Riou, Y., Dano, C., et al., 2012. Single- and multiobjective genetic algorithm optimization for identifying soil parameters. International Journal for Numerical and Analytical Methods in Geomechanics, 36(5):597-618. http://dx.doi.org/10.1002/nag.1019

Sheng, D., Sloan, S., Yu, H., 2000. Aspects of finite element implementation of critical state models. Computational Mechanics, 26(2):185-196. http://dx.doi.org/10.1007/s004660000166

Wang, L., Yin, Z., 2015. Stress dilatancy of natural soft clay under an undrained creep condition. International Journal of Geomechanics, 15(5):A4014002. http://dx.doi.org/10.1061/(ASCE)GM.1943-5622.0000271

Yin, Z.Y., Hicher, P.Y., 2008. Identifying parameters controlling soil delayed behaviour from laboratory and in situ pressuremeter testing. International Journal for Numerical and Analytical Methods in Geomechanics, 32(12): 1515-1535. http://dx.doi.org/10.1002/nag.684

Yin, Z.Y., Chang, C.S., 2009. Microstructural modelling of stress-dependent behaviour of clay. International Journal of Solids and Structures, 46(6):1373-1388. http://dx.doi.org/10.1016/j.ijsolstr.2008.11.006

Yin, Z.Y., Karstunen, M., 2011. Modelling strain-ratedependency of natural soft clays combined with anisotropy and destructuration. Acta Mechanica Solida Sinica, 24(3):216-230. http://dx.doi.org/10.1016/S0894-9166(11)60023-2

Yin, Z.Y., Wang, J.H., 2012. A one-dimensional strain-rate based model for soft structured clays. Science China Technological Sciences, 55(1):90-100. http://dx.doi.org/10.1007/s11431-011-4513-y

Yin, Z.Y., Chang, C.S., Karstunen, M., et al., 2010a. An anisotropic elastic-viscoplastic model for soft clays. International Journal of Solids and Structures, 47(5):665-677. http://dx.doi.org/10.1016/j.ijsolstr.2009.11.004

Yin, Z.Y., Karstunen, M., Hicher, P.Y., 2010b. Evaluation of the influence of elasto-viscoplastic scaling functions on modelling time-dependent behaviour of natural clays. Soils and Foundations, 50(2):203-214. http://dx.doi.org/10.3208/sandf.50.203

Yin, Z.Y., Chang, C.S., Hicher, P.Y., 2010c. Micromechanical modelling for effect of inherent anisotropy on cyclic behaviour of sand. International Journal of Solids and Structures, 47(14-15):1933-1951. http://dx.doi.org/10.1016/j.ijsolstr.2010.03.028 
Yin, Z.Y., Karstunen, M., Chang, C.S., et al., 2011a. Modeling time-dependent behavior of soft sensitive clay. Journal of Geotechnical and Geoenvironmental Engineering, 137(11):1103-1113. http://dx.doi.org/10.1061/(ASCE)GT.1943-5606.0000527

Yin, Z.Y., Hattab, M., Hicher, P.Y., 2011b. Multiscale modeling of a sensitive marine clay. International Journal for Numerical and Analytical Methods in Geomechanics, 35(15):1682-1702.

http://dx.doi.org/10.1002/nag.977

Yin, Z.Y., Xu, Q., Chang, C.S., 2013. Modeling cyclic behavior of clay by micromechanical approach. Journal of Engineering Mechanics, 139(9):1305-1309. http://dx.doi.org/10.1061/(ASCE)EM.1943-7889.0000516

Yin, Z.Y., Zhu, Q.Y., Yin, J.H., et al., 2014. Stress relaxation coefficient and formulation for soft soils. Géotechnique Letters, 4(1):45-51.

http://dx.doi.org/10.1680/geolett.13.00070

Yin, Z.Y., Xu, Q., Yu, C., 2015a. Elastic viscoplastic modeling for natural soft clays considering nonlinear creep. International Journal of Geomechanics, 15(5):A6014001. http://dx.doi.org/10.1061/(ASCE)GM.1943-5622.0000284

Yin, Z.Y., Yin, J.H., Huang, H.W., 2015b. Rate-dependent and long-term yield stress and strength of soft Wenzhou marine clay: experiments and modeling. Marine Georesources and Geotechnology, 33(1):79-91. http://dx.doi.org/10.1080/1064119X.2013.797060

Zeng, L.L., 2010. Deformation Mechanism and Compression Model of Natural Clays. PhD Thesis, Southeast University, Nanjing, China (in Chinese).

Zhu, Q.Y., Jin, Y.F., Yin, Z.Y., et al., 2013. Influence of natural deposition plane orientation on oedometric consolidation behavior of three typical clays from southeast coast of China. Journal of Zhejiang University-SCIENCE A (Applied Physics \& Engineering), 14(11):767-777.
http://dx.doi.org/10.1631/jzus.A1300156

Zhu, Q.Y., Wu, Z.X., Li, Y.L., et al., 2014. A modified creep index and its application to viscoplastic modelling of soft clays. Journal of Zhejiang University-SCIENCE A (Applied Physics \& Engineering), 15(4):272-281. http://dx.doi.org/10.1631/jzus.A1300331

\section{中文概要}

题 目: 一个结构性软土参数的确定方法

目 的: 软土流变和结构破坏的相互耦合导致结构性软土 的参数难以准确得到。本文拟建立一个有效的参 数确定方法, 期望仅基于常规的室内试验得到可 靠的、合理的本构参数。

创新点：1. 通过采用优化方法来实现结构性软土参数的确 定; 2 . 仅基于常规的室内试验得到本构参数; 3 . 采 用最近提出的考虑各向异性、流变和结构破坏的 超应力本构模型。

方 法: 1. 建立数值模拟和试验数据之间的误差计算公 式; 2. 通过流变本构模拟室内常规试验, 并计算 模拟误差; 3. 采用下山单纯形法 (simplex) 优化 方法, 寻找模拟误差的最小值; 此最小值对应的 这组模拟参数即为土体的最优参数; 4 . 利用最优 参数模拟其他类型的试验, 验证参数的合理性和 可靠性。

结 论: 本文提出的优化程序可以有效的找到结构性土体 的流变和结构破坏参数, 并且找到的参数非常的 合理。

关键词: 黏土; 流变; 结构破坏; 优化; 参数确定 